\title{
Immethridine, histamine $\mathrm{H}_{3}$-receptor $\left(\mathrm{H}_{3} \mathrm{R}\right)$ agonist, alleviated experimental autoimmune encephalomyelitis via inhibiting the function of dendritic cells
}

\author{
Yaru Shi ${ }^{1, *}$, Zhenlong Li ${ }^{1, *}$, Ran Chen ${ }^{1}$, Jiang Zhang ${ }^{1}$, Xuefei Hu ${ }^{1}$, Cong He ${ }^{1}$, Qiong \\ $\mathrm{Su}^{1}$, Hongdou Ma ${ }^{1}$, Hua Ren ${ }^{1}$, Min Qian ${ }^{1}$, Shufang Cui ${ }^{2}$ and Wenzheng Jiang ${ }^{1}$ \\ ${ }^{1}$ Shanghai Key Laboratory of Regulatory Biology, School of Life Sciences, East China Normal University, Shanghai, China \\ ${ }^{2}$ Laboratory Animal Center, Second Military Medical University, Shanghai, China \\ *These authors have contributed equally to this work \\ Correspondence to: Wenzheng Jiang, email: wzjiang@bio.ecnu.edu.cn \\ Shufang Cui, email: youngstar_sf@163.com \\ Keywords: multiple sclerosis, EAE, H3R, immethridine, dendritic cell \\ Received: August 23, $2016 \quad$ Accepted: July 29, $2017 \quad$ Published: August 24, 2017 \\ Copyright: Shi et al. This is an open-access article distributed under the terms of the Creative Commons Attribution License 3.0 \\ (CC BY 3.0), which permits unrestricted use, distribution, and reproduction in any medium, provided the original author and source \\ are credited.
}

\section{ABSTRACT}

Multiple sclerosis (MS) is an inflammatory disease that is characterized by immune-mediated demyelination and degeneration of the central nervous system (CNS). Experimental autoimmune encephalomyelitis (EAE) is the preferential experimental rodent model for MS. Previous study demonstrated histamine H3 receptor (H3R) was an important factor in pathophysiology of EAE and immethridine was the most selective agonist of H3R. However, whether immethridine has therapeutic effect on EAE and its mechanism remained to be defined. Here we constructed EAE mouse model by immunization of MOG $_{35-55}$ peptides with complete Freund's adjuvant, immethridine was used to treat EAE and its therapeutic effect was evaluated. The results showed that the treatment of immethridine could alleviate EAE. The percentage of Th1 and Th17 in the spleen from the treated EAE mice decreased and the surface molecules such as CD40, CD86 or MHCII on dendritic cells (DCs) were also down-regulated. To understand the effect of immethridine on DCs, bone marrow-derived DCs were prepared and the immunological functions were analyzed. The data demonstrated that immethridine could change the expression profiles of cytokines in DCs and inhibit the expression of the co-stimulatory molecules such as CD40 and CD86. Furthermore, immethridine also inhibited the antigen-presenting function of DCs and T cell differentiation induced by DCs. Signaling pathway analysis demonstrated that the phosphorylation of NF-KB p65 but not ERK1/2 in DCs was inhibited after the treatment of immethridine. These data strongly suggested that immethridine could inhibit the function of DCs and indicated the therapeutic potential on EAE.

\section{INTRODUCTION}

Multiple sclerosis (MS) belongs to a T cell-mediated autoimmune disease which is characterized by chronic inflammatory demyelination and neurodegeneration of the central nervous system (CNS) [1]. The young adults between 20 and 40 years of age are usually onset [2]. The socioeconomic importance of the disease is second only to trauma in young adults although it is usually not life-threatening [3-5]. Due to disease complexity and heterogeneity, the pathogenesis of MS remains unknown and the specific effective treatments have not yet been 
developed. Experimental autoimmune encephalomyelitis (EAE), which shares many pathological and histological similarities with MS and is a widely used animal model for MS, provides crucial evidence of autoimmune mechanisms [6-8].

Dendritic cells (DCs) are the most potent antigen presenting cells (APCs) in both the innate and adaptive immune responses. In peripheral tissues, immature DCs have strong ability to capture antigens (Ags) and undergo a maturation process upon contact with stress factors such as TNF- $\alpha$ or lipopolysaccharide (LPS). The matured DCs lose their capacity to process Ags, but they have higher level of co-stimulatory molecule expression, produce cytokines, and migrate to the lymphoid organs to prime naive Ag-specific T cells $[9,10]$. In EAE, DCs play a dual role. Firstly, they activate naïve antigen-specific $\mathrm{CD}^{+} \mathrm{T}$ cells and induce them to differentiate into Th1 and Th17 effector cells in peripheral lymphoid organs. Secondly, DCs re-stimulate migrating encephalitogenic $\mathrm{T}$ cells in the perivascular space of the CNS and facilitate their infiltration into the CNS parenchyma [11].

Histamine [2-(4-imidazole) ethylamine] is a ubiquitous inflammatory mediator and has diverse physiological processes, such as neurotransmission, secretion of pituitary hormones, and regulation of the gastrointestinal and circulatory systems, etc. It has been reported that histamine can modulate immune responses and plays a key regulatory role in EAE or MS [12]. Histamine exerts several physiological functions by activating distinct subtypes of histamine receptors. The histamine receptors, such as $\mathrm{H} 1, \mathrm{H} 2, \mathrm{H} 3, \mathrm{H} 4$ receptors, belong to members of $\mathrm{G}$ protein-coupled receptor (GPCR) families $[13,14]$. H3R is one of the important histamine receptors and it was discovered as the autoreceptor, which regulated the secretion and generation of histamine [15]. The expression of H3R is expressed not only in CNS, but also in other tissues and cells such as lung, cardiovascular system, intestine or DCs [12]. Teuscher et al. have reported that $\mathrm{H} 3 \mathrm{R}-\mathrm{KO}$ mice developed more severe EAE disease compared with wide-type B6 mice, [16]. H3R antagonists have been applied for the therapy on several diseases and CNS disorders, such as attentiondeficit hyperactivity disorder (ADHD), Alzheimer's disease, epilepsy, schizophrenia, and obesity. On the other hand, the therapeutic applications of H3R agonists for myocardial ischemia, inflammatory, and gastric acid related diseases have also been reported [17]. Immethridine dihydrobromide is a strong and highly selective histamine $\mathrm{H} 3$ receptor agonist that displays 300 fold selectivity over the $\mathrm{H} 4$ receptor and does not bind to $\mathrm{H} 1$ or $\mathrm{H} 2$ receptors at concentrations up to $10 \mu \mathrm{M}$ [18], immethridine plays an opposite effect against the gastric lesions induced by HCL in rats [19, 20].

So far, the pathogenesis of MS or EAE remains unknown, the effective treatments have not yet been developed. Since H3R-KO mice have developed more serious EAE [16], it is very meaningful to address whether immethridine, a strong and highly selective agonist of H3R, has the therapeutic effect on EAE. In this study, the data showed that immethridine inhibited the functions of DC cells and reduced the severity of EAE.

\section{RESULTS}

\section{The treatment of immethridine reduced the severity of EAE}

To evaluate whether H3R agonist immethridine could alleviate the severity of EAE, EAE mice were induced with $\mathrm{MOG}_{35-55}$ immunization and the treatment of immethridine was performed. The EAE mice treated with immethridine had lower clinical scores than the control EAE mice (Figure 1A), which showed that the treatment of immethridine significantly reduced the severity of EAE. Histological examination of the spinal cords was performed at day 21. Compared to the control EAE mice, the treated EAE mice with immethridine had fewer inflammatory infiltrates in spinal cord (Figure 1B) and a decrease of demyelination in histological analysis of spinal cord (Figure 1C). Splenocytes were isolated from immethridine-treated and untreated EAE mice and the expression of pro-inflammatory cytokines was analyzed by RT-PCR (Figure 1D) and Q-PCR (Figure 1E), respectively. The result showed that lower level of TNF- $\alpha$, IFN- $\gamma$ and IL-17A was detected in immethridine-treated mice. Taken together, these data suggested that immethridine could alleviate the severity of EAE.

\section{Immethridine treatment affected the immune cells in EAE mice}

Th1 and Th17 cells play a crucial pathological role in EAE [21, 22]. The splenocytes were isolated from spleen of immethridine-treated and control EAE mice on day 21 post-immunization and analyzed for Th1, Th17 and Treg by intracellular staining of IFN- $\gamma$, IL-17A or Foxp3, respectively. We found that the percentage of Th1 and Th17 subgroups in $\mathrm{CD} 4^{+}$ population was significantly lower in the spleen of immethridine-treated mice compared to control EAE mice (Figure 2A), but there was no significant difference for Treg cells (data not shown). Moreover, splenocytes were isolated from EAE mice and $\mathrm{MOG}_{35-55}$-specific $\mathrm{T}$ cell proliferation was also investigated, the data showed that a lower level of cell proliferation was detected for $\mathrm{T}$ cells from immethridine-treated mice (Figure 2B). DCs play an important role in the development of inflammatory responses in MS/EAE [11], we therefore analyzed the expression of co-stimulatory molecules on DCs in splenocytes from immethridinetreated and control EAE mice. Interestingly, the lower expression of co-stimulatory molecules such as CD40 
and CD86 on DCs from immethridine-treated EAE mice was detected (Figure 2C). The expression level of MHCII on DCs in spinal cord was also detected and the expression of MHCII on DCs in spinal cord from immethridine-treated EAE mice was down-regulated compared to control EAE mice (Figure 2D), which indicated that immethridine could affect the function of DCs. Furthermore, the immune cells and CD4 ${ }^{+} \mathrm{T}$ cell subsets in spinal cord were also analyzed by FACS. The data showed that there was no significant difference for the numbers of DCs, CD4 and $\mathrm{CD}^{+} \mathrm{T}$ cells between immethridine-treated EAE mice and untreated mice (data not shown). However, there were fewer Th1 and Th17 cells in spinal cord from immethridine-treated EAE mice (Figure 2E).

\section{Immethridine affected the cytokine expression profiles in BMDCs}

DCs can produce an ample repertoire of cytokines and mediate diverse immune responses through the secreted cytokines. Previously studies showed that histamine could inhibit LPS-induced IL-12 production by DCs and the effect was mediated through both H1R and H2R [23]. Although the expression of H3R on DCs was controversial, it has been detected in DCs by RTPCR in current study and the expression level of H3R was down-regulated after DCs were activated by LPS stimulation (data not shown), which was consistent with the previous report [24]. To understand if immethridine, the highly selective agonist of H3R, could affect the cytokine expression in DCs, the bone marrow-derived dendritic cells (BMDC) were prepared. At day 6, DCs were stimulated with immethridine $(1 \mu \mathrm{M})$ and LPS $(100 \mathrm{ng} / \mathrm{ml})$ in $24-w e l l$ plates for $6 \mathrm{~h}$. After the cells were collected, total mRNAs were extracted and RT-PCR was performed to detect the expression of cytokines such as IL-6, TGF- $\beta$ and IL-12 P40. The data showed that immethridine-treated DCs had lower expression level of IL-6, TGF- $\beta$ and IL-12 P40 compared to PBS (Figure $3 \mathrm{~A}$ ), and the data were confirmed by Q-PCR (Figure 3B) and ELISA (Figure 3C). Taken altogether, these results suggested that immethridine could inhibit cytokine production in DCs.

\section{Immethridine inhibited DC-induced Th1/Th17 differentiation}

DCs play a vital role in initiating the innate immune response by production of cytokines, these cytokines play an important role in promoting $\mathrm{CD}^{+} \mathrm{T}$ cells to differentiate into different $\mathrm{T}$ cell subsets such as Th1, Th2, Th17, etc. To verify if the treatment of immethridine affected $\mathrm{T}$ cell differentiation induced by $\mathrm{DCs}$, the purified naïve $\mathrm{CD} 4^{+} \mathrm{T}$ cells were mixed with DCs at a ratio of 10:1 for $72 \mathrm{~h}$. The percentage of Th1
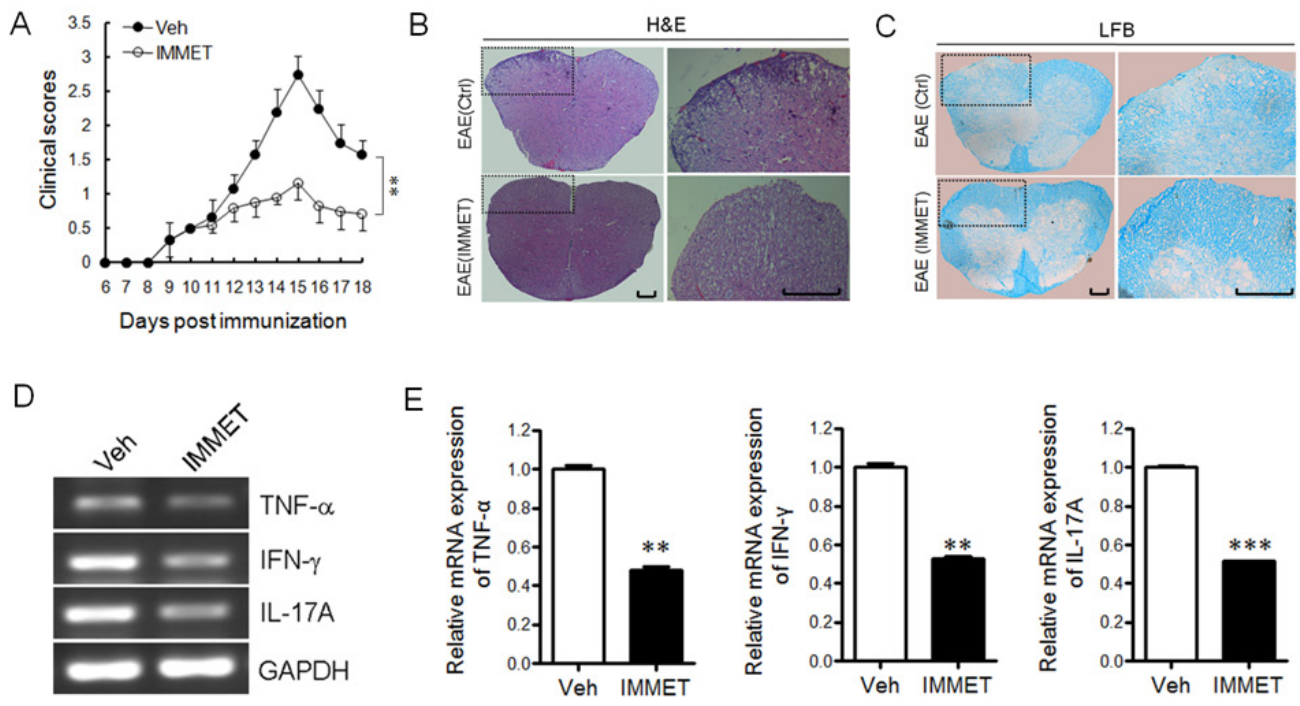

Figure 1: H3R agonist immethridine could alleviate the severity of EAE. (A) EAE mice were treated with immethridine (15 mg/ $\mathrm{kg})$ every other day via i.p. from day 8 post-immunization. Control groups were given PBS injection. Data $\operatorname{are} \operatorname{mean} \pm \mathrm{SD}(\mathrm{n}=6)$. $* * \mathrm{p}<0.01$ versus vehicle. (B) H\&E staining and (C) LFB staining of paraffin sections of spinal cords. After the mice ( $\mathrm{n}=6$ ) were sacrificed on day 21 , the spinal cord samples were isolated from vehicle and immethridine-treated EAE mice and fixed in 4\% (w/v) paraformaldehyde for 48h, then the paraffin-embedded sections were stained with hematoxylin-eosin or luxol fast blue. Scale bar, $100 \mu \mathrm{m}$. (D) RT-PCR analysis of the pro-inflammatory cytokines of splenocytes. The splenocytes from vehicle and immethridine-treated EAE mice were collected after the mice were sacrificed on day 21 and the total RNAs were extracted. RT-PCR was performed with the specific primers of cytokines and the PCR products were analyzed on a 1\% agarose gel stained with ethidium bromide. (E) Q-PCR analysis of the pro-inflammatory cytokines of splenocytes. $* * \mathrm{p}<0.01, * * * \mathrm{p}<0.001$ versus vehicle. Data are representative of three independent experiments. 
and Th17 cells was analyzed by intracellular staining with FITC-labeled anti-IFN- $\gamma$ or FITC-labeled anti-IL17A, the data indicated that the percentage of Th1 and Th17 in $\mathrm{CD}^{+}$population was significantly lower in immethridine-treated DCs compared to the control DCs (Figure 4A and Figure 4B).

\section{Immethridine inhibits the expression of surface molecules and antigen-presentation ability of BMDCs}

During the maturation process, DCs up-regulate the expression of cell surface molecules, such as CD40,
A
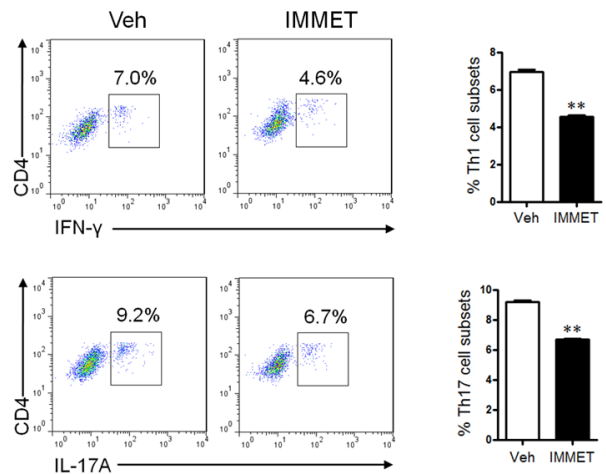

C
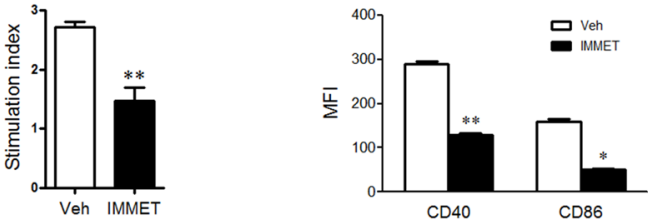

D
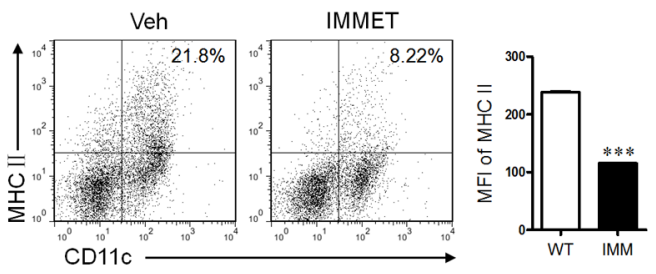

E
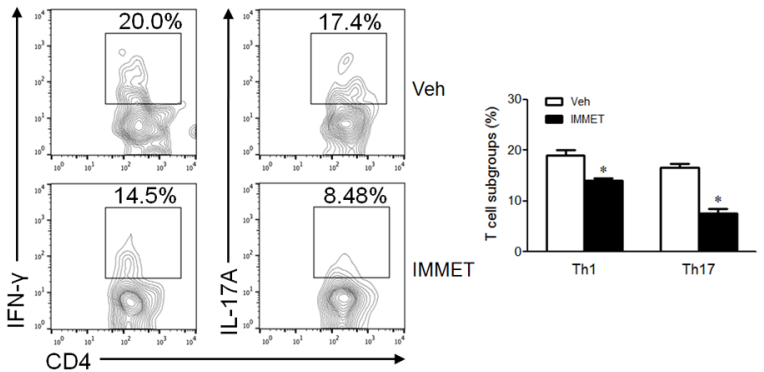

Figure 2: The treatment of immethridine could affect the differentiation and function of immune cells in EAE mice. (A) FACS analysis of $\mathrm{CD}^{+} \mathrm{T}$ cell subsets in splenocytes of EAE mice $(\mathrm{n}=6)$. Splenocytes were prepared and Th1 and Th17 cells were analyzed by intracellular staining of IFN- $\gamma$ and IL-17A, respectively, in the $\mathrm{CD}^{+}{ }^{+}$gate. ${ }^{*} \mathrm{p}<0.05, * * \mathrm{p}<0.01$ versus vehicle. (B) MTT analysis of $\mathrm{MOG}_{35-55}$-specific $\mathrm{T}$ cell proliferation. Splenocytes of EAE mice $(\mathrm{n}=6)$ were isolated and cultured at the present or absent of $\mathrm{MOG}_{35-55}$ peptides for $72 \mathrm{~h}$ and T cell proliferation was measured using a MTT Cell Proliferation Assay Kit. The data were shown at stimulation index. ${ }^{*} \mathrm{p}<0.01$ versus vehicle. (C) FACS analysis of expression of co-stimulatory molecules on DCs in splenocytes of EAE mice ( $\mathrm{n}=6$ ). Splenocytes were prepared and stained with fluorescent labeled-antibodies against CD11c, CD40 or CD86, the stained cells were analyzed on flow cytometry. $* p<0.05, * * p<0.01$ versus vehicle. (D) FACS analysis of expression of MHCII on DCs in spinal cord of EAE mice $(n=6)$. Immune cells in spinal cord were prepared and stained with fluorescent labeled-antibodies against CD11c, MHCII, the stained cells were analyzed on flow cytometry. ${ }^{* * *} \mathrm{p}<0.001$ versus vehicle. (E) FACS analysis of CD4 ${ }^{+} \mathrm{T}$ cell subsets in spinal cord of EAE mice ( $\mathrm{n}=6$ ). The lymphocytes from spinal cord were prepared and Th1 and Th17 cells were analyzed by intracellular staining of IFN- $\gamma$ and IL-17A, respectively, in the $\mathrm{CD} 4^{+}$gate. ${ }^{*} \mathrm{p}<0.05$ versus vehicle. Data are representative of three independent experiments. 
CD80, and CD86, that is important for interaction with $\mathrm{B}$ and $\mathrm{T}$ cells and subsequent development of the adaptive immune response [25, 26]. The expression of surface molecules on DCs was analyzed by FACS, the date showed that immethridine could inhibit the expression of CD40 (Figure 5A), CD86 (Figure 5B) in immature or matured DCs, which indicated that the treatment of immethridine could inhibit the maturation of DCs. DCs are crucial antigen-presenting cells (APCs) for primary $\mathrm{T}$-cell response, these cells are critically important in triggering an effective adaptive immune response. To understand whether immethridine affected the antigen presenting ability of DCs, MOG-pulsed DCs were co-cultured with MOG-specific $\mathrm{CD}^{+} \mathrm{T}$ and
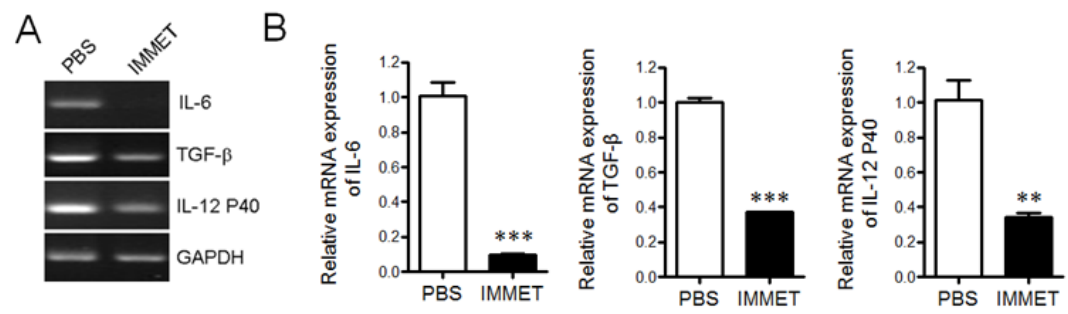

C
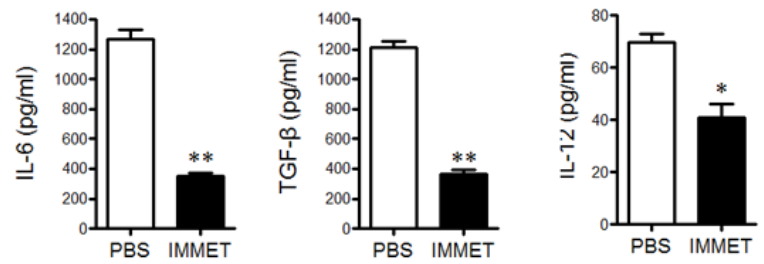

Figure 3: Immethridine could inhibit the cytokine secretion in BMDCs. BMDCs were prepared and stimulated with immethridine $(1 \mu \mathrm{M})$ and LPS $(100 \mathrm{ng} / \mathrm{ml})$ in 24 -well plates for $6 \mathrm{~h}$. The total mRNAs were extracted and the transcription level of the cytokines was detected by RT-PCR (A) and Q-PCR (B), respectively. The culture supernatant was collected and the protein level of the cytokines was measured by ELISA (C). ${ }^{*} \mathrm{p}<0.05,{ }^{* *} \mathrm{p}<0.01,{ }^{* * *} \mathrm{p}<0.001$ versus PBS. Data are representative of three independent experiments.
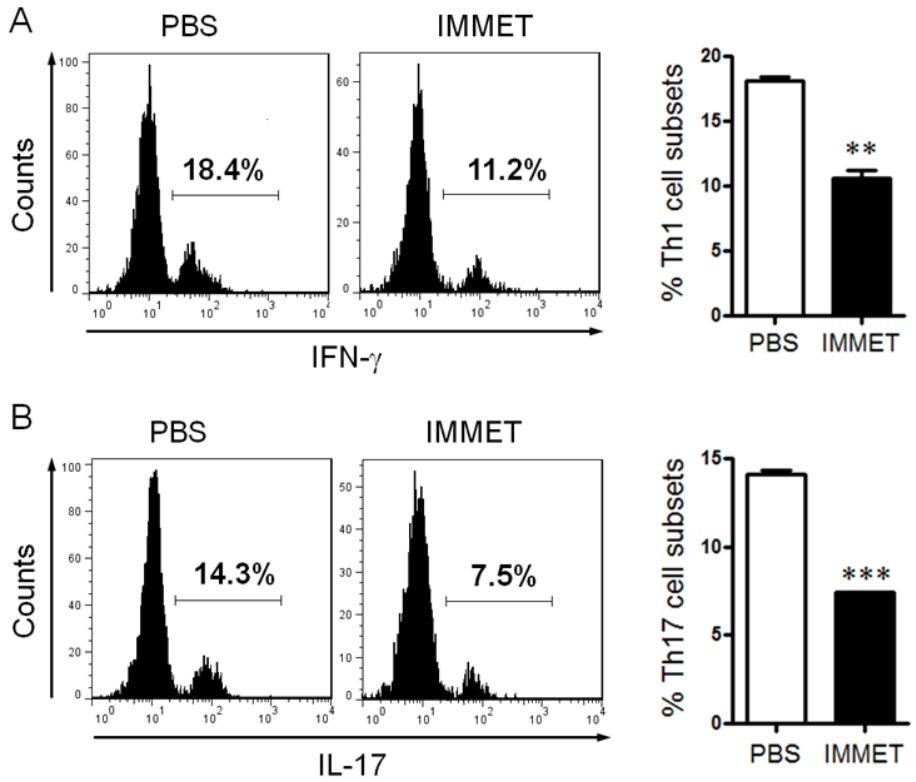

Figure 4: Immethridine could affect DC-induced $\mathbf{C D 4}{ }^{+} \mathbf{T}$ cell differentiation. BMDCs were prepared and stimulated with immethridine $(1 \mu \mathrm{M})$ and LPS $(100 \mathrm{ng} / \mathrm{ml})$ for $24 \mathrm{~h}$, and naïve CD4 ${ }^{+} \mathrm{T}$ cells were separated from splenocytes with Mouse CD4 Negative Selection Kit. After BMDCs and naïve CD4 ${ }^{+}$T cells were co-cultured at a ratio of for $72 \mathrm{~h}$, Th1 cells (A) and Th17 cells (B) were analyzed by intracellular staining of IFN- $\gamma$ and IL-17A in the $\mathrm{CD}^{+}$gate. $* * \mathrm{p}<0.01, * * * \mathrm{p}<0.001$ versus PBS. Data are representative of three independent experiments. 
$\mathrm{T}$ cell proliferation was detected by MTT kit (Figure 5C). The results showed that immethridine-treated DCs could induce less $\mathrm{T}$ cell proliferation compared to the control DCs, which indicated that the antigen-presenting ability of DCs could be inhibited by immethridine. Mixed lymphocyte reaction (MLR) was also performed and the result demonstrated that immethridine-treated DCs had lower ability to stimulate allogeneic T-cell proliferation compared to the untreated DCs (Figure 5D). Taken together, these results strongly suggested that immethridine could inhibit the immunological functions of DC cells.

\section{Immethridine inhibited the expression of TLR4/ CD14 and phosphorylation of NF-кB p65}

TLR4 and co-receptor CD14 play important roles in LPS signaling pathway and involve in the expression of surface molecules on DCs [27]. The expression of TLR4 and CD14 in DCs was analyzed by RT-PCR (Figure 6A) and Q-PCR (Figure 6B), respectively. The result showed that immethridine could down-regulate the expression of TLR4 and CD14. To further understand the signaling pathway involved in the down-regulation of the surface

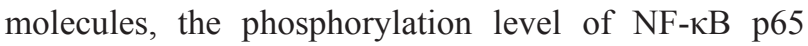

A

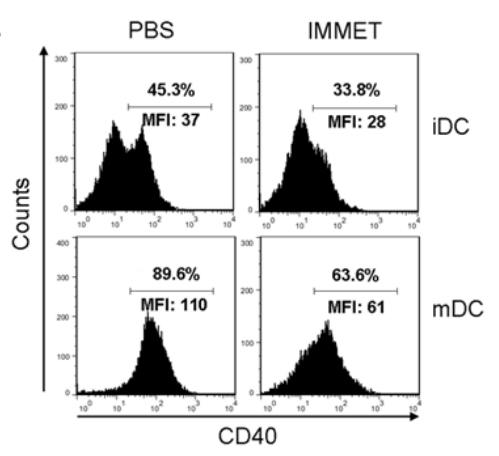

B

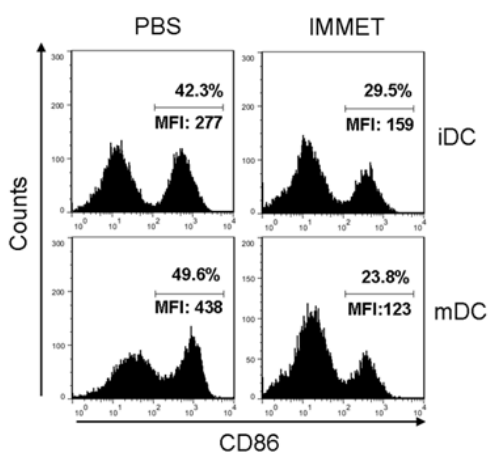

C

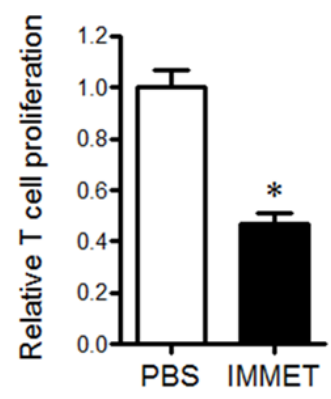

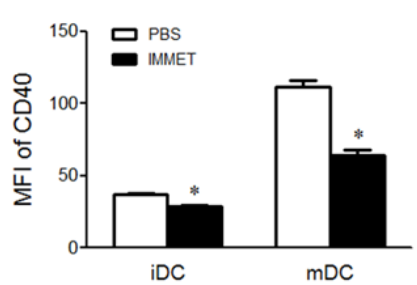

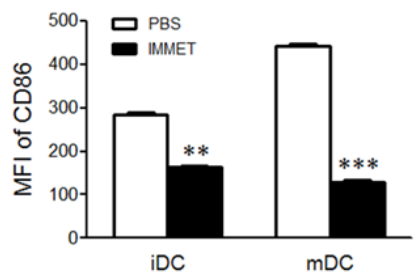

$D$

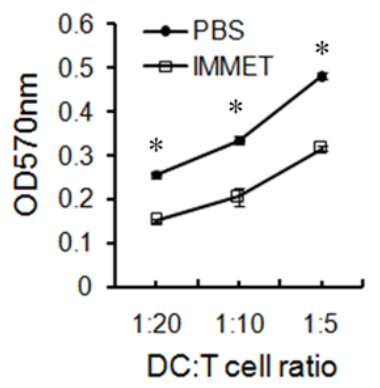

Figure 5: Immethridine could inhibit the function of BMDCs. FACS analysis of CD40 and CD86 on BMDCs. Immature DCs were exposed to combinations of immethridine and/or LPS for $12 \mathrm{~h}$, and cells were stained with a FITC-labeled anti-CD11c and PE-labeled anti-CD40 (A) or anti-CD86 (B), then the results were analyzed by FACS. ${ }^{* *} \mathrm{p}<0.01,{ }^{* * *} \mathrm{p}<0.001$ versus PBS. Data are representative of three experiments. (C) Immethridine inhibited the capacity of antigen-presentation of DCs. MOG-pulsed DCs was co-cultured with MOG-specific CD4 ${ }^{+} \mathrm{T}$ for $72 \mathrm{~h}$ and $\mathrm{T}$ cell proliferation was detected by MTT Cell Proliferation Assay Kit. The data were shown in relative T cell proliferation. ${ }^{*} p<0.05$ versus PBS. (D) MLR assay. Purified T cells from BALB/C mice and immethridine-treated or untreated DCs were co-cultured for 5 days and T cell proliferation was detected by MTT Cell Proliferation Assay Kit. The data was shown in OD value at $570 \mathrm{~nm} .{ }^{*} \mathrm{p}<0.05$ versus PBS. Data are representative of three experiments. 
and ERK1/2 was analyzed by western blot, the data demonstrated that the phosphorylation of NF- $\mathrm{KB}$ p 65 but not ERK1/2 was significantly inhibited by the treatment of immethridine (Figure 6C).

\section{DISCUSSION}

Multiple sclerosis (MS) is an inflammatory neurodegenerative disease caused by autoimmune attack against myelin [28]. So far, the understanding of the pathogenesis of MS is still very limited. Currently, some drugs, such as interferon $\beta$, glatirmer acetate, mitoxantrone, natalizumab and so on, have been used in MS patients [29, 30]. However, these treatments can not treat MS completely because of low efficiency or lifethreatening side effects, it is very important to find out new candidate drugs for MS therapy.

It is now known that histamine takes part in several physiological and pathological processes, such as the allergic skin reactions, septic inflammation, etc [31]. The functions of histamine are mediated through four G-protein coupled receptors (H1R, H2R, H3R, H4R). So far, many GPCRs including histamine receptors are reported to play important roles in the pathogenesis of MS [32]. H1R and H4R stimulation leads to worsening of MS, whereas the signaling activation of H2R and H3R leads to amelioration of disease [12]. According to the reports from Teuscher et al., the deficiency of H3R could aggravate EAE symptom in mice [16]. Therefore, H3R may be a potential target to treat MS/EAE. To address the possibility of H3R as a target for MS treatment, EAE mouse model was induced and the therapy was performed with immethridine, a strong and highly selective histamine $\mathrm{H} 3$ receptor agonist. The results showed that immethridine-treated EAE mice had lower clinical scores and less pathological characteristics. These data strongly suggested that immethridine had the therapeutic effect on EAE. Furthermore, we also evaluated cytokine expression and $T$ cell subgroups of splenocytes in EAE mice, the data indicated that lower level of IFN- $\gamma$ and IL-17A and less Th1 and Th17 cells were detected in immethridine-treated EAE mice. However, H3R didn't express on T cells and it has been confirmed by RT-PCR in current study (data not shown).

Dendritic cells (DCs) link innate immunity and adaptive immunity as professional antigen presenting cells (APCs) and play important roles in maintaining central and peripheral tolerance [33], the functional abnormal of DCs can lead to various autoimmune and neuroinflammatory diseases [34-36]. Interestingly, lower level of surface molecule expression was detected in immethridinetreated mice. To understand if immethridine can affect the functions of DCs and present the therapeutic effect on EAE, bone marrow-derived dendritic cells (BMDCs) were prepared and the biological functions of DCs were studied with or without immethridine. The results of cytokine
A

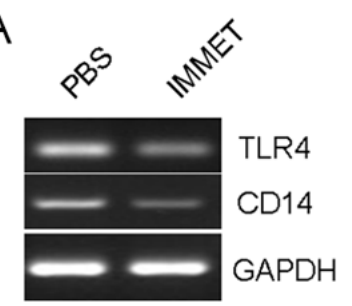

C

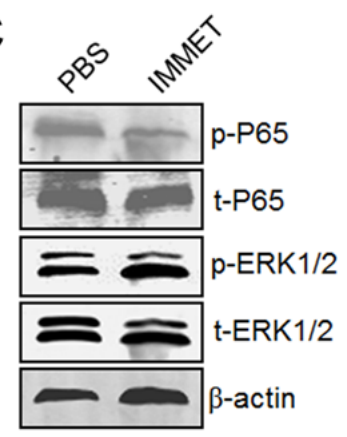

$\mathrm{B}$

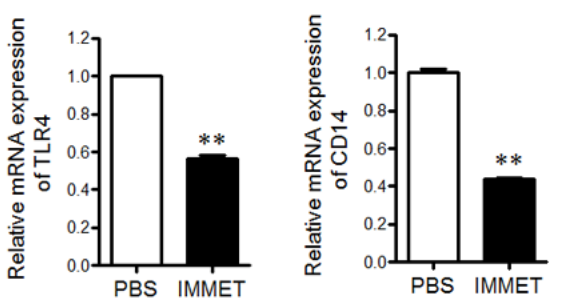

Figure 6: Immethridine could inhibit the signaling pathway by LPS stimulation. (A) RT-PCR analysis of the expression of TLR4 and CD14. DCs were treated with $100 \mathrm{ng} / \mathrm{ml}$ of LPS and $1 \mu \mathrm{M}$ of immethridine for $12 \mathrm{~h}$, then the total RNAs were extracted and RT-PCR was performed using the specific primers. The PCR products were analyzed on a $1 \%$ agarose gel stained with ethidium bromide. (B) Q-PCR analysis of the expression of TLR4 and CD14. ${ }^{*} \mathrm{p}<0.01$ versus PBS. (C) Western blot analysis of signaling pathway. The cell protein was prepared after DCs were treated with immethridine, SDS-PAGE were performed and the separated protein was electro-transferred onto nitrocellulose membrane and stained by anti-mouse primary antibodies and HRP-conjugated secondary antibodies, respectively. Data are representative of three experiments. 
expression showed that immethridine could inhibit the cytokine secretion such as IL-12, IL-6 and TGF- $\beta$, which were associated with the differentiation of Th1 and Th17. And the result has also been verified by cell differentiation assay. The results of cell differentiation suggested that the cell culture supernatant derived from immethridine-treated DCs could induce more Naïve $\mathrm{CD}^{+} \mathrm{T}$ cells to differentiate into Th1 and Th17, which played important roles in the pathogenesis of MS/EAE [37, 38]. The expression level of surface molecules such as CD40 and CD86 is closely related to the maturation of DCs. In the study, we found that immethridine could inhibit the expression of CD40 and CD86 both in immature or LPS-stimulated DCs, which meant that the maturation of DCs could be inhibited by the activation of H3R with immethridine. The ability of antigen presentation of DCs was assayed in vitro and the results indicated the treatment of immethridine reduced the function of antigen presentation and the inhibitory effect has also been detected in MLR assay. The maturation of DCs could be induced by LPS stimulation via activating $\mathrm{NF}-\kappa \mathrm{B}$ or MAPK signaling pathway [39, 40]. To understand what kind of signaling pathway was involved in the function of immethridine, the signaling pathway of $\mathrm{NF}-\kappa \mathrm{B}$ and MAPK was analyzed and the results indicated that immethridine could reduce the expression of TLR-4 and CD14, which are receptor or co-receptor of LPS, and down-regulate the phosphorylation of NF- $\kappa \mathrm{B}$ p 65 but not ERK1/2.

In summary, our data demonstrated that immethridine had therapeutic effect on EAE and could inhibit the function of DCs through activating H3R, such as cytokine production, surface molecule expression, $\mathrm{T}$ cell differentiation, and antigen-presenting ability. As the pathogenesis of MS or EAE remains unknown, effective treatments need to be developed, our results may provide a new therapeutic target for MS/EAE.

\section{MATERIALS AND METHODS}

\section{Mice}

Female C57BL/6 mice of 8-10 weeks old were purchased from Laboratory Animal Center of East China Normal University. Animal care and experimental procedures were carried out following the guidelines of the institutional Animal Ethics Committee of East China Normal University.

\section{EAE induction and treatment}

EAE model was induced as previously described [41]. Briefly, Female mice at $8-10$ wk of age were immunized subcutaneously in the flanks with $200 \mu \mathrm{g}$ of $\mathrm{MOG}_{35-55}$ peptides (purity $>98 \%$, GL Biochem Ltd., Shanghai) which were emulsified in complete Freund's adjuvant (CFA) containing $500 \mu \mathrm{g}$ of Mycobacterium tuberculosis H37RA (Difco Laboratories, USA). Furthermore, $400 \mathrm{ng}$ of pertussis toxin (PTX, List Biological Laboratories, USA) in $100 \mu \mathrm{l}$ PBS-50 mM $\mathrm{NaCl}$ was intraperitoneally injected on the day of immunization and $24 \mathrm{~h}$ later. For the treatment of EAE, immethridine dihydrobromide (Sigma-Aldrich, USA) was administered at $15 \mathrm{mg} / \mathrm{kg}$ i.p. every other day after the observable sign of EAE occurred. Mice were monitored every day using the following arbitrary scale: 0 , no symptom; 1, limp tail; 2, limp tail and wobbly gait; 3, bilateral hind limb paralysis; 4, complete hind limb and partial fore limb paralysis; 5, Death.

\section{Histopathological analysis}

On day 21, animals were humanly euthanatized and their sera, spleen, brain hemisphere (without the cerebellum) and the spinal cord were isolated for subsequent experiments. Spinal cord samples were then fixed in $4 \%(\mathrm{w} / \mathrm{v})$ paraformaldehyde for $48 \mathrm{~h}$. Paraffinembedded sections were stained with hematoxylin-eosin (H\&E) or luxol fast blue (LFB) to analyze inflammation or demyelination, respectively.

\section{MOG-specific $\mathbf{T}$ cell proliferation assay}

For ex vivo assay, splenocytes were isolated from immethridine-treated or control EAE mice and cultivated in triplicates in complete RPMI1640 media (with 10\% FBS) at $2 \times 10^{5}$ per well in 96 -well plates in presence or absence of the $\mathrm{MOG}_{35-55}$ peptide $(20 \mu \mathrm{g} / \mathrm{ml})$, all cultures were maintained at $37{ }^{\circ} \mathrm{C}$ in $5 \% \mathrm{CO}_{2}$ for $72 \mathrm{~h}$. $\mathrm{T}$ cell proliferation was measured using a MTT Cell Proliferation Assay Kit (Beyotime, China). Briefly, $10 \mu \mathrm{l}$ of MTT (methylthiazolyldiphenyl-tetrazolium bromide) solution (5 $\mathrm{mg} / \mathrm{ml}$ ) was added to each well and incubated for further $4 \mathrm{~h}$. $100 \mu \mathrm{l}$ of formazan solvent was added to each well and incubated until all formazan was dissolved and the absorbance was evaluated by a microplate reader at 570 $\mathrm{nm}$. The results were expressed as a stimulation index (SI, SI=OD570 of experimental cells / OD570 of negative control), which indicates significant proliferation if $\mathrm{SI} \geq 2$.

\section{Analysis of $\mathrm{CD4}^{+} \mathrm{T}$ cell subgroups and DCs in the spleen of EAE mice}

Splenocytes from immethridine-treated or control EAE mice were collected, washed, and incubated in Red Blood Cell Lysis Buffer at room temperature for 5 min, single cell suspensions were prepared. $\mathrm{CD} 4^{+} \mathrm{T}$ cell subgroups were detected by intracellular cytokine staining (ICCS) as previously described. Briefly, the cells were washed and restimulated with $10 \mathrm{ng} / \mathrm{ml}$ PMA (Sigma) plus $1 \mu \mathrm{g} / \mathrm{ml}$ ionomycin (Calbiochem, San Diego, CA) for $5 \mathrm{~h}$. Brefeldin A (Sigma, $10 \mu \mathrm{g} / \mathrm{ml}$ ) was added during the last $2 \mathrm{~h}$ of culture. After the surface staining with 
FITC-labeled anti-CD4 mAb (BD Biosceince), cells were fixed, permeabilized, stained with PE-labeled anti-IFN- $\gamma$, anti-IL-17A mAb or anti-Foxp3 mAb (BD Biosciences), and analyzed on a flow cytometer (Becton Dickinson, USA) using CellQuest software (BD Biosciences). The expression of surface molecules were detected with FITC-labeled anti-CD11c mAb (BD Biosciences) and PElabeled anti-CD40, anti-CD86 or anti-MHCII mAb (BD Biosciences).

\section{Preparation of bone marrow-derived dendritic cells}

Bone marrow-derived dendritic cells (BMDCs) were prepared as described previously [42]. Briefly, femurs and tibias of 6-8 week-old mice were removed and isolated from the surrounding muscle tissue using sterile instruments. The bones were washed three times with phosphate-buffered saline $(1 \times \mathrm{PBS})$, and then the bone marrow was flushed with RPMI-1640 media (HyClone, USA) using a 1-ml syringe. After the red blood cells were lysed with Red Blood Cell Lysis Buffer, whole bone marrow cells were counted. Cells obtained from femurs and tibias were cultured at a final concentration of $1 \times 10^{6}$ cells $/ \mathrm{ml}$ in six-well plates in the culture media containing RPMI-1640, 10\% fetal bovine serum (FBS) (HyClone, USA), $10 \mathrm{ng} / \mathrm{ml}$ recombinant murine GM-CSF (Peprotech, USA), 1 ng/ml IL-4 (Peprotech, USA), 1 U/ $\mathrm{ml}$ penicillin and $1 \mu \mathrm{g} / \mathrm{ml}$ streptomycin, at $37^{\circ} \mathrm{C}, 5 \% \mathrm{CO}_{2}$ for 6 days. Then the media were replaced with fresh, prewarmed complete media at day 2 and day 4 to remove non-adherent cells. On day 6, maturation of immature DCs was induced by the addition of $100 \mathrm{ng} / \mathrm{mL}$ LPS.

To analyze the purity of DCs, the cells were stained with FITC-labeled anti-CD11c mAb (BD Biosciences, San Jose, CA) and analyzed by flowcytometry. The purity of DCs was up to $85-90 \%$.

\section{RT-PCR or quantitative real-time PCR analysis of gene expression}

Total RNAs were extracted using Trizol Reagent (Takara, Japan) and the reverse transcription was performed using Prime-ScriptTM RT Reagent Kit according to the manufacturer's instructions (Takara, Japan). The mRNA expression was determined by RTPCR or quantitative real-time PCR (Q-PCR). PCR products were analyzed on a $1 \%$ agarose gel stained with ethidium bromide. Q-PCR was conducted in the LightCycler Quantitative PCR Apparatus (Illumina, USA) using the SYBR Green Master Mix (Toyobo, Japan) and the results were presented as fold increases relative to the expression of house keeping GAPDH. The following primer pairs were used: IL-6, forward, 5'- TTCTTGGGACTGATGCTG-3', and reverse, 5'-CTGGCTTTGTCTTTCTTGTT--3'; TGF- $\beta$, forward,
5'-CCGCAACAACGCCATCT-3', and reverse, 5'-GCCCTGTATTCCGTCTCCTT-3'; IL-12 P40, forward, 5'-CCAAGAACTTGCAGATGAAGC-3', and reverse, 5'-TTCCTTTCCAACGTTGCATC-3'; TNF- $\alpha$, forward, 5'-TCCCTTTCACTCACTGGC-3', and reverse, 5'-ACTTGGTGGTTTGCTACG-3'; IFN- $\gamma$, forward, 5'-CACTGCATCTTGGCTTTGCA-3', and reverse, 5'-GCTGAT GGCCTGATTGTCTTTC-3'; IL-17A, forward, 5'-CTCAAAGCTCAGCGTGTCCAA-3', and reverse, 5'-TCATGTGGTGGTCCAGCTTTC-3'; TLR4, forward, 5'-ATGGCATGGCTTACACCACC-3', and reverse, 5'-GAGGCCAATTTTGTCTCCACA-3'; CD14, forward, 5'-CTCTGTCCTTAAAGCGGCTTAC-3', and reverse, 5'-GTTGCGGAGGTTCAAGATGTT-3'; GAPDH, forward, 5'-GGGCATCTTGGGCTACACT-3', and reverse, 5'-GCCGAGTTGGGATAGGG-3'.

\section{ELISA analysis of cytokine production}

DCs were stimulated with immethridine $(1 \mu \mathrm{M})$ and LPS $(100 \mathrm{ng} / \mathrm{ml})$ for $72 \mathrm{~h}$, the supernatants were collected and stored at $-80{ }^{\circ} \mathrm{C}$ until the cytokine measurements. The assays for IL-6, TGF- $\beta$ and IL-12 were performed with ELISA kits from eBioscience according to the manufacturers' protocol.

\section{FACS analysis of surface molecule expression}

Immature DCs exposed to combinations of immethridine $(1 \mu \mathrm{M})$ and/or LPS $(100 \mathrm{ng} / \mathrm{ml})$ for $12 \mathrm{~h}$ were stained with a FITC-labeled anti-CD11c and PElabeled anti-CD40 or anti-CD86 (BD Biosciences, San Jose, CA). FACS analysis was performed on a flow cytometer (Becton Dickinson, USA) using CellQuest software (BD Biosciences). Results are expressed as mean fluorescent density (MFI).

\section{T cell differentiation induced by DCs}

DCs were treated with immethridine $(1 \mu \mathrm{M})$ and LPS (100 ng/ml) for 24h. Naïve $\mathrm{CD}^{+} \mathrm{T}$ cells were prepared by Mouse CD4 Negative Selection Kit (Stemcell Technology, Canada) from spleens of C57BL/6 mice and co-cultured with immethridine-treated or untreated DCs at a ratio of $10: 1$ for $72 \mathrm{~h}$ at the present of $0.5 \mu \mathrm{g} / \mathrm{ml}$ antiCD3 $\mathrm{mAb}$ and $5 \mu \mathrm{g} / \mathrm{ml}$ anti-CD28 $\mathrm{mAb}$ (BD Biosciences). The percentage of Th1 and Th17 cells was analyzed by intracellular staining with FITC-labeled anti-IFN- $\gamma$ or FITC-labeled anti-IL-17A (BD Biosciences, San Jose, CA).

\section{Antigen-presentation assay}

DCs were incubated with immethridine and $\mathrm{MOG}_{35}$ ${ }_{55}(20 \mu \mathrm{g} / \mathrm{ml})$ for $4 \mathrm{~h}$. After washed with PBS, DCs were stimulated with LPS $(100 \mathrm{ng} / \mathrm{ml})$ for $12 \mathrm{~h} .1 \times 10^{6}$ of 
$\mathrm{CD}^{+} \mathrm{T}$ cells, isolated from splenocytes of EAE mice with Mouse CD4 Negative Selection Kit (Stemcell Technology, Canada), were co-cultured with $1 \times 10^{5}$ of $\mathrm{MOG}_{35-55}$ peptide-pulsed DCs at a ratio of 10:1 ratio in 96-well round bottom plates for $72 \mathrm{~h}$. Finally, cells were analyzed by MTT Cell Proliferation Assay Kit according to the manufacturer's instructions.

\section{Mixed lymphocyte reaction (MLR)}

$\mathrm{T}$ cells were purified from splenocytes of BALB/c mouse using T cell Enrichment Columns (R\&D Systems, Minneapolis, MN) and were used as responders $\left(1 \times 10^{5} /\right.$ well). The bone marrow-derived DCs from C57BL/6 mice were prepared as before. The harvested DCs were treated with immethridine $(1 \mu \mathrm{M})$ or PBS for $4 \mathrm{~h}$ in a humidified atmosphere with $5 \% \mathrm{CO}_{2}$ at $37^{\circ} \mathrm{C}$. Then DCs were treated with $30 \mu \mathrm{g} / \mathrm{ml}$ Mitomycin C (Sigma, USA) for $45 \mathrm{~min}$. After being washed 3 times by RPMI 1640, they were used as stimulators. For the induction of allogeneic MLR, purified $\mathrm{T}$ cells were co-cultured with immethridinetreated or untreated allogeneic DCs at the DC/T cell ratio of 1:5, 1:10 and 1:20 in triplicate in flat-bottom 96-well microplates. Negative control received only $\mathrm{T}$ cells and media. The plates were incubated at $37{ }^{\circ} \mathrm{C}$ in a humid atmosphere with $5 \% \mathrm{CO}_{2}$ for 5 days and the result was measured by MTT Cell Proliferation Kit (Beyotime, China) according to the manufacturer's instructions.

\section{Western blot analysis of signaling pathway}

DCs were treated with $100 \mathrm{ng} / \mathrm{ml}$ LPS and $1 \mu \mathrm{M}$ immethridine for $12 \mathrm{~h}$ and the whole-cell extracts were prepared by RIPA buffer supplemented with different kinds of proteinase inhibitors. Proteins were loaded onto a $8 \%$ SDS-polyacrylamide gel and subjected to electrophoresis. The separated proteins were electrotransferred onto a nitrocellulose membrane using a Mini Trans-Blot apparatus (Bio-Rad). The membrane was then blocked with skimmed milk and probed with specific antibodies against p65 (pSer536-p65), ERK1/2 (pThr202/ Tyr204-ERK1/2) (Cell Signaling Technology, USA).

\section{Statistical analysis}

Student's t test was used to analyze the differences between different groups. Data were presented as mean \pm standard deviation (SD). Difference was considered statistically significant when $\mathrm{p}<0.05$.

\section{Abbreviations}

ADHD: attention-deficit hyperactivity disorder; Ag: antigens; APC: antigen presenting cells; BMDC: bone marrow-derived dendritic cells; CNS: central nervous system; DC: dendritic cell; EAE: experimental autoimmune encephalomyelitis; GPCR: G protein- coupled receptor; $\mathrm{H}_{3} \mathrm{R}$ : histamine $\mathrm{H}_{3}$-receptor; LPS: lipopolysaccharide; MLR: mixed lymphocyte reaction; MS: multiple sclerosis; Q-PCR: quantitative real-time PCR.

\section{Author contributions}

YS, ZL, RC, JZ, XH, CH, QS, and HM performed the experiments, collected the data; HR, MQ provided technical support; YS and WJ wrote the manuscript; SC and WJ supervised and financed the study.

\section{ACKNOWLEDGMENTS}

This work was supported by National Key Research and Development Program of China [2016YFC1200400]; Technology Innovation Action Plan of Shanghai Municipal Science and Technology Commission (14140904200); National Natural Science Foundation of China [81072459, 81771306]; Program for New Century Excellent Talents in University [NCET-12-0179]; National Key Technology Research and Development Program of the Ministry of Science and Technology of China [2015BAI09B00].

\section{CONFLICTS OF INTEREST}

The authors have no financial conflicts of interest.

\section{REFERENCES}

1. Lassmann H. Models of multiple sclerosis: new insights into pathophysiology and repair. Curr Opin Neurol. 2008; 21:242-247.

2. Rosati G. The prevalence of multiple sclerosis in the world: an update. Neurol Sci. 2001; 22:117-139.

3. Compston A, Coles A. Multiple sclerosis. Lancet. 2002; 359:1221-1231.

4. Frohman EM, Racke MK, Raine CS. Multiple sclerosisthe plaque and its pathogenesis. N Engl J Med. 2006; 354:942-955.

5. Noseworthy JH, Lucchinetti C, Rodriguez M, Weinshenker BG. Multiple sclerosis. N Engl J Med. 2000; 343:938-952.

6. Slavin A, Kelly-Modis L, Labadia M, Ryan K, Brown ML. Pathogenic mechanisms and experimental models of multiple sclerosis. Autoimmunity. 2010; 43:504-513.

7. Gu SM, Park MH, Yun HM, Han SB, Oh KW, Son DJ, Yun JS, Hong JT. CCR5 knockout suppresses experimental autoimmune encephalomyelitis in C57BL/6 mice. Oncotarget. 2016; 7:1538215393. https://doi.org/10.18632/oncotarget.8097.

8. Quintana A, Müller M, Frausto RF, Ramos R, Getts DR, Sanz E, Hofer MJ, Krauthausen M, King NJ, Hidalgo J, Campbell IL. Site-specific production of IL-6 in the central nervous system retargets and enhances the inflammatory response in experimental autoimmune encephalomyelitis. J Immunol. 2009; 183:2079-2088. 
9. Cella M, Sallusto M, Lanzavecchia A. Origin, maturation and antigen presenting function of dendritic cells. Curr Opin Immunol. 1997; 9:10-16.

10. Banchereau J, Steinman RM. Dendritic cells and the control of immunity. Nature. 1998; 392:245-252.

11. Bailey SL, Schreiner B, McMahon EJ, Miller SD. CNS myeloid DCs presenting endogenous myelin peptides 'preferentially' polarize $\mathrm{CD}^{+} \mathrm{T}(\mathrm{H})-17$ cells in relapsing EAE. Nat Immunol. 2007; 8:172-180.

12. Jadidi-Niaragh F, Mirshafiey A. Histamine and histamine receptors in pathogenesis and treatment of multiple sclerosis. Neuropharmacology. 2010; 59:180-189.

13. Cherifi Y, Pigeon C, Le Romancer M, Bado A, ReylDesmars F, Lewin MJ. Purification of a histamine H3 receptor negatively coupled to phosphoinositide turnover in the human gastric cell line HGT1. J Biol Chem. 1992; 267:25315-25320.

14. Nakamura T, Itadani H, Hidaka Y, Ohta M, Tanaka K. Molecular cloning and characterization of a new human histamine receptor, H4R. Biochem Biophys Res Commun. 2000; 279:615-620.

15. Arrang JM, Garbarg M, Schwartz JC. Auto-inhibition of brain histamine release mediated by a novel class (H3) of histamine receptor. Nature. 1983; 302:832-837.

16. Teuscher C, Subramanian M, Noubade R, Gao JF, Offner H, Zachary JF, Blankenhorn EP. Central histamine H3 receptor signaling negatively regulates susceptibility to autoimmune inflammatory disease of the CNS. Proc Natl Acad Sci U S A. 2007; 104:10146-10151.

17. Kitbunnadaj R, Zuiderveld OP, De Esch IJ, Vollinga RC, Bakker R, Lutz M, Spek AL, Cavoy E, Deltent MF, Menge WM, Timmerman H, Leurs R. Synthesis and structureactivity relationships of conformationally constrained histamine H3 receptor agonists. J Med Chem. 2003; 46:5445-5457.

18. Kitbunnadaj R, Zuiderveld OP, Christophe B, Hulscher S, Menge WM, Gelens E, Snip E, Bakker RA, Celanire S, Gillard M, Talaga P, Timmerman H, Leurs R. Identification of 4-(1H-imidazol-4(5)-ylmethyl) pyridine (immethridine) as a novel, potent, and highly selective histamine $\mathrm{H}(3)$ receptor agonist. J Med Chem. 2004; 47:2414-2417.

19. Coruzzi G, Adami M, Pozzoli C, de Esch IJ, Smits R, Leurs R. Selective histamine $\mathrm{H} 3$ and $\mathrm{H} 4$ receptor agonists exert opposite effects against the gastric lesions induced by $\mathrm{HCl}$ in the rat stomach. Eur J Pharmacol. 2011; 669:121-127.

20. Adami M, Pozzoli C, Leurs R, Stark H, Coruzzi G. Histamine $\mathrm{H}(3)$ receptors are involved in the protective effect of ghrelin against $\mathrm{HCl}$-induced gastric damage in rats. Pharmacology. 2010; 86:259-266.

21. de Oliveira DM, de Oliveira EM, Ferrari Mde F, Semedo P, Hiyane MI, Cenedeze MA, Pacheco-Silva A, Câmara NO, Peron JP. Simvastatin ameliorates experimental autoimmune encephalomyelitis by inhibiting Th1/Th17 response and cellular infiltration. Inflammopharmacology. 2015; 23:343-354.

22. Chong WP, Horai R, Mattapallil MJ, Silver PB, Chen J, Zhou R, Sergeev Y, Villasmil R, Chan CC, Caspi RR. IL-27p28 inhibits central nervous system autoimmunity by concurrently antagonizing Th1 and Th17 responses. J Autoimmun. 2014; 50:12-22.

23. Caron G, Delneste Y, Roelandts E, Duez C, Bonnefoy JY, Pestel J, Jeannin P. Histamine polarizes human dendritic cells into Th2 cell-promoting effector dendritic cells. J Immunol. 2001; 167:3682-3686.

24. Amaral MM, Davio C, Ceballos A, Salamone G, Cañones C, Geffner J, Vermeulen M. Histamine improves antigen uptake and cross-presentation by dendritic cells. J Immunol. 2007; 179:3425-3433.

25. Das M, Kaveri SV, Bayry J. Cross-presentation of antigens by dendritic cells: role of autophagy. Oncotarget. 2015; 6:28527-28528. https://doi.org/10.18632/oncotarget.5268.

26. Ni K, O'Neill HC. The role of dendritic cells in $\mathrm{T}$ cell activation. Immunol Cell Biol. 1997; 75:223-230.

27. Li J, Liu Z, Jiang S, Cortesini R, Lederman S, Suciu-Foca N. T suppressor lymphocytes inhibit NF-kappa B-mediated transcription of CD86 gene in APC. J Immunol. 1999; 163:6386-6392.

28. Bruck W, Kuhlmann T, Stadelmann C. Remyelination in multiple sclerosis. J Neurol Sci. 2003; 206:181-185.

29. Brinkmann V, Billich A, Baumruker T, Heining $P$, Schmouder R, Francis G, Aradhye S, Burtin P. Fingolimod (FTY720): discovery and development of an oral drug to treat multiple sclerosis. Nat Rev Drug Discov. 2010; 9:883-897.

30. Compston A, Coles A. Multiple sclerosis. Lancet. 2008; 372:1502-1517.

31. Radvány Z, Darvas Z, Kerekes K, Prechl J, Szalai C, Pállinger E, Valéria L, Varga VL, Sandor M, Erdei A, Falus A. H1 histamine receptor antagonist inhibits constitutive growth of Jurkat $\mathrm{T}$ cells and antigen-specific proliferation of ovalbumin-specific murine T cells. Semin Cancer Biol. $2000 ; 10: 41-45$.

32. Du $\mathrm{C}, \mathrm{Xin} \mathrm{X}$. G protein-coupled receptors as therapeutic targets for multiple sclerosis. Cell Res. 2012; 22:1108-1128.

33. Moser M. Dendritic cells in immunity and tolerance-do they display opposite functions? Immunity. 2003; 19:5-8.

34. Manuel SL, Rahman S, Wigdahl B, Khan ZK, Jain P. Dendritic cells in autoimmune diseases and neuroinflammatory disorders. Front Biosci. 2007; 12:4315-4335.

35. Wu GF, Laufer TM. The role of dendritic cells in multiple sclerosis. Curr Neurol Neurosci Rep. 2007; 7:245-252.

36. Xue Z, Li W, Wang H, Huang B, Ge Z, Gu C, Liu Y, Zhang K, Yang J, Han R, Peng M, Li Y, Zhang D, et al. ZSTK474, a novel PI3K inhibitor, modulates human CD14+ 
monocyte-derived dendritic cell functions and suppresses experimental autoimmune encephalomyelitis. J Mol Med. 2014; 92:1057-1068.

37. Rostami A, Ciric B. Role of Th17 cells in the pathogenesis of CNS inflammatory demyelination. J Neurol Sci. 2013; 333:76-87.

38. Yan L, Hu F, Yan X, Wei Y, Ma W, Wang Y, Lu S, Wang Z. Inhibition of microRNA-155 ameliorates experimental autoimmune myocarditis by modulating Th17/Treg immune response. J Mol Med. 2016; 94:1063-1079.

39. Peters M, Guidato PM, Peters K, Megger DA, Sitek B, Classen B, Heise EM, Bufe A. Allergy-protective arabinogalactan modulates human dendritic cells via C-type lectins and inhibition of NF-кB. J Immunol. 2016; 196:1626-1635.
40. Takenaka MC, Araujo LP, Maricato JT, Nascimento VM, Guereschi MG, Rezende RM, Quintana FJ, Basso AS. Norepinephrine controls effector $\mathrm{T}$ cell differentiation through $\beta 2$-adrenergic receptor-mediated inhibition of NF- $\kappa \mathrm{B}$ and AP-1 in dendritic cells. J Immunol. 2016; 196:637-644.

41. Zhang J, Li Z, Hu X, Su Q, He C, Liu J, Ren H, Qian M, Liu J, Cui S, Jiang W. Knockout of P2Y12 aggravates experimental autoimmune encephalomyelitis in mice via increasing of IL-23 production and Th17 cell differentiation by dendritic cells. Brain Behav Immun. 2017; 62:245-255.

42. Jiang W, Chen R, Kong X, Long F, Shi Y. Immunization with adenovirus LIGHT-engineered dendritic cells induces potent $\mathrm{T}$ cell responses and therapeutic immunity in HBV transgenic mice. Vaccine. 2014; 32:4565-4570. 